\title{
ASPECTOS SEMÂNTICO-DISCURSIVOS DA RENOVAÇÃO LEXICAL EM ÉPOCA DE LAVA JATO E GOVERNO BOLSONARO
}

\author{
SEMANTIC-DISCURSIVE ASPECTS OF LEXICAL \\ RENEWAL IN THE ERA OF LAVA JATO AND \\ BOLSONARO GOVERNMENT
}

\author{
André Crim Valente* \\ Universidade do Estado do Rio de Janeiro, Rio de Janeiro, RJ, Brasil
}

\begin{abstract}
Resumo: A renovação lexical sempre esteve presente na linguagem literária. Na atualidade, o processo de criação vocabular apresenta exemplos diários na linguagem midiática. Os neologismos formais ou vocabulares vêm sendo utilizados em diversos segmentos da mídia, o que também ocorre, em menor escala, com os neologismos semânticos ou conceituais. Neste artigo, os tipos de criaçõoes neológicas são abordados em uma perspectiva teórica que busca a integraçã̃o entre léxico e discurso. 0 corpus analisado contém dez neologismos referentes à operação Lava Jato e ao governo Bolsonaro.
\end{abstract}

Palavras-chave: léxico; discurso; neologismo; sentido; mídia impressa.

Abstract: Lexical renewal has always been present in literary language. At present, the vocabulary creation process presents daily examples in the media language. Formal or vocabular neologisms have been used in various segments of the media, which also occurs to a lesser extent with semantic or conceptual neologisms. In this article, the types of neological creations are approached from a theoretical perspective that seeks the integration between lexicon and discourse. The corpus analyzed contains ten neologisms referring to the operation Lava Jato and the Bolsonaro government.

Keywords: Lexicon; Speech; Neologism; Sense; Print Media.

* Professor titular da Universidade do Estado do Rio de Janeiro - UERJ, Rio de Janeiro, RJ, Brasil; prof.acvalente@gmail.com

http://dx.doi.org/10.11606/issn.2236-4242.v32i3p79-97 
Linha D’Água (Online), São Paulo, v. 32, n. 3, p. 79-97, set.-dez. 2019

\section{Introdução}

A renovação lexical na mídia tem suplantado as criações neológicas na literatura, o que não ocorria até meados do século XX. Com o desenvolvimento da linguagem midiática na segunda metade do século passado e nas primeiras décadas do século XXI, pode-se afirmar, hoje, que são os profissionais de comunicação que mais contribuem para a ampliação do nosso léxico. Colabora em tal processo a própria segmentação da linguagem jornalística, dividida em várias áreas: cultura, esporte, economia e política, entre outras. A última terá prioridade na pesquisa aqui apresentada. Serão analisados neologismos utilizados pela mídia em meados de 2019 nas matérias e colunas políticas sobre a operação Lava Jato e o novo governo - de Jair Bolsonaro - eleito em outubro de 2018.

Para a análise do corpus, far-se-á um recorte nas teorias sobre estudos lexicológicos sobre produção lexical e se dará destaque aos conceitos de neologia de forma, neologia de sentido, neologia intertextual e palavras portmanteau. As obras destacadas são de autores frequentemente estudados pelos pesquisadores do Grupo de Trabalho (GT) de Lexicologia, Lexicografia e Terminologia da Associação Nacional de Pós-Graduação e Pesquisa em Letras e Linguística (ANPOLL), grupo a que pertenço. Como também faço parte do Círculo Interdisciplinar de Análise do Discurso (CIAD), a análise dos neologismos combinará léxico e discurso, ou seja, será desenvolvida em uma perspectiva linguístico-discursiva.

\section{Neologia da forma}

Os neologismos são criados, fundamentalmente, a partir do sistema linguístico, da língua. O principal recurso criativo é a utilização dos elementos mórficos do vocábulo. Os processos de criação de palavras, com destaque para a composição e a derivação, são responsáveis pela criação de grande parte neologismos. Há matrizes morfológicas - bases ou moldes para a criação de palavras - que explicam tanto os neologismos como os termos já existentes na língua. Existem matrizes para substantivos, adjetivos, verbos e advérbios.

Apresenta-se a seguir a revisão da literatura na área de morfologia, com destaque para quatro grandes obras.

VALENTE, A. C. Aspectos semântico-discursivos da renovação lexical em época de Lava Jato e governo Bolsonaro 
Linha D’Água (Online), São Paulo, v. 32, n. 3, p. 79-97, set.-dez. 2019

\subsection{Morfologia (Claudio Cezar Henriques)}

O autor dedica a Parte III (a última) do seu livro aos Processos de Formação. Lembra que a Nomenclatura Gramatical Brasileira (NGB) faz referência apenas aos seguintes termos: derivação, composição e hibridismo. A seguir, destaca da seguinte forma os dois processos principais de formação de palavras em português:

radical $1+$ radical $=$ palavra $3>$ composição radical $1+$ afixo = palavra $2>$ derivação (HENRIQUES, 2007, p. 115).

$\mathrm{Na}$ composição, além da justaposição e da aglutinação, menciona a supercomposição: quando se reúne num único vocábulo formal um verdadeiro conglomerado de radicais.

Ex. Comigo-ninguém-pode (nome de planta)

Quatro-salafrários-contra-uma-velhinha (texto em O Globo sobre o filme "Matadores de velhinha") (HENRIQUES, 2007, p. 116)

$\mathrm{Na}$ derivação, destaca a prefixação, a sufixação e a parassíntese, com exaustivo estudo sobre o último processo.

Apresenta três processos especiais: a regressão, a abreviação (ou braquissemias) e a reduplicação (ou redobro).

Chama de pseudoprocesso a conversão ou derivação imprópria, que considera fenômeno de estilística morfossintática.

Encerra o estudo com outros casos: siglas e abreviaturas; neologismos; combinação de processos (unidades complexas); cruzamento morfológico e fracionamento vocabular.

\subsection{Morfologia portuguesa (José Lemos Monteiro)}

O autor não faz um estudo em separado com o título Processos de formação de palavras (MONTEIRO, 1987). Trata da Derivação Nominal, da Derivação Verbal, de Regras de Derivação e faz um inventário de sufixos. Aborda a composição e a

VALENTE, A. C. Aspectos semântico-discursivos da renovação lexical em época de Lava Jato e governo Bolsonaro 
Linha D’Água (Online), São Paulo, v. 32, n. 3, p. 79-97, set.-dez. 2019

recomposição. Merece destaque a inusitada abordagem de J. L. Monteiro (1987) sobre aglutinação e justaposição. Julga um equívoco tomá-las como aspectos peculiares ou propriedades da composição. Considera-as processos fonológicos, não morfológicos. Elas estão presentes tanto na composição como na derivação.

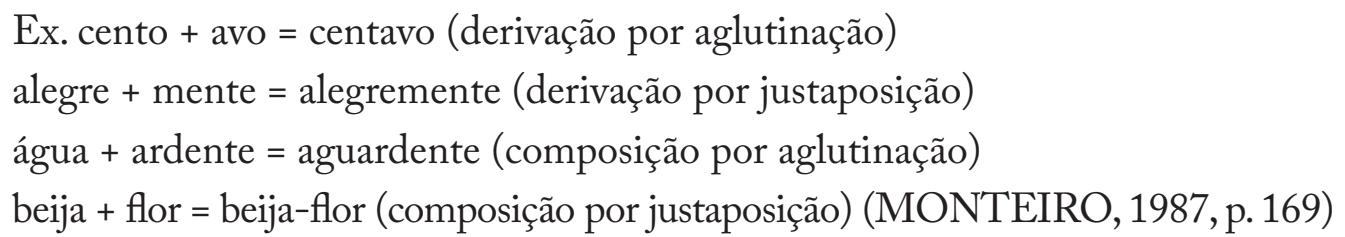

Monteiro (1987) ainda apresenta a braquissemia e a acrossemia. A primeira é o emprego de parte de um vocábulo pelo vocábulo inteiro - "moto" e "pólio"(MONTEIRO, 1987, p. 174) -, e a segunda consiste na combinação de sílabas ou fonemas extraídos dos elementos de um nome composto ou de uma expressão “elepê" e "MOBRAL" (MONTEIRO, 1987, p. 175).

Apresenta, ainda, os casos de fonossemia, também chamada de ecoísmo e ideofonia -"miau" e "toc-toc" (MONTEIRO, 1987, p. 177) -, e de duplicação, também chamada de redobro, redobramento, reduplicação - "reco-reco" e "titio" (MONTEIRO, 1987, p. 178).

\subsection{Manual de Morfologia do Português (Maria Nazaré de Carvalho Laroca)}

A autora apresenta quatro processos morfossintáticos: a derivação, a composição, a redução e a reduplicação. Considera mais produtivos os dois primeiros. Destaca três tipos de derivação:
a) Prefixal > prefixo + palavra-base
b) Sufixal > palavra-base + sufixo
c) Parassintética > prefixo + palavra-base + sufixo (LAROCA, 1994, p. 84)

Destaca a presença de neoprefixos - "macro", "mega" e "pseudo" - (LAROCA, 1994, p. 86-87); de pseudoprefixos - "tele", "auto" e "foto" (LAROCA, 1994, 
Linha D’Água (Online), São Paulo, v. 32, n. 3, p. 79-97, set.-dez. 2019

p. 87) - e de neo-sufixos - "dromo", "logia" e "ete" (LAROCA, 1994, p. 88), esse a partir de chacrete.

Divide a composição em vocabular e sintagmática. A primeira corresponde à junção de duas ou mais palavras e pode ser feita por justaposição (jogo-treino; quebra-mola), por aglutinação (planalto; Mariângela) e por truncação, também chamada blend ou palavra-pormanteau (showmício; cantriz).

A composição sintagmática é apresentada com base nos estudos de Ieda M. Alves e de Maria T. C. Biderman. Essa chamou de lexias complexas os sintagmas lexicalizados, como "produção independente" "cesta básica" e "crimes de colarinho branco"(LAROCA, 1994, p. 90).

Maria de Nazaré de C. Laroca afirma que a redução abrange a derivação regressiva, a abreviação vocabular e a acronimia.

Conclui seu estudo destacando que o processo de reduplicação, ou duplicação silábica, é chamado de onomatopeia por Celso Cunha.

\subsection{Teoria lexical (Margarida Basílio)}

Na sua obra de 1987, ainda atualíssima, a autora dedica três partes ao tema: Processos gerais de formação, Outros processos de formação, Formação de palavras na lingua escrita e na lingua falada.

Na primeira, aborda a derivação e a composição. Destaca que "o processo de derivação se caracteriza pela junção de um afixo (sufixo ou prefixo) a uma base para a formação de uma palavra" (BASÍLIO, 1987, p. 26). Observa que, em geral, a base é uma forma livre - livro + eiro; re + ler (BASÍLIO, 1987, p. 26) -, mas também reconhece casos de derivação a partir de bases presas - psicolo $+i c o$ (BASÍLIO, 1987, p. 27).

O processo de composição se caracteriza, segundo Basílio, pela junção de uma base a outra para a formação de uma palavra - guarda + chuva; agri+cultura (BASÍLIO, 1987, p. 27) -, com a utilização de forma livre (chuva) ou presa (agri-).

Ao trabalhar com funções sintático-semânticas e a noção de estrutura para distinguir derivação de composição, a autora o faz com extrema clareza. Enquanto a derivação envolve um afixo, que é um elemento estável, com função sintática ou

VALENTE, A. C. Aspectos semântico-discursivos da renovação lexical em época de Lava Jato e governo Bolsonaro 
Linha D’Água (Online), São Paulo, v. 32, n. 3, p. 79-97, set.-dez. 2019

semântica predeterminada, o que caracteriza e define a função do processo de composição é a sua estrutura "de tal maneira que, das bases que se junta para formar uma palavra, cada uma tem seu papel definido pela estrutura” (BASÍLIO, 1987, p. 29).

Nos outros processos de formação, Margarida Basílio (1987) estuda as seguintes derivações: regressiva, imprópria e parassintética. Estabelece significativa distinção entre derivação regressiva e abreviação, com uma perspicaz observação não encontrada nas gramáticas. $\mathrm{Na}$ redução ou abreviação, a palavra formada é "sinônima da derivante, apenas sendo usada, as mais das vezes, num estilo mais coloquial (boteco, granfa, delega)" (BASÍLIO, 1987, p. 37).

$\mathrm{Na}$ derivação parassintética, explora as formações com o sufixo -ado, como em “desalmado" (BASÍLIO, 1987, p. 43), para destacar-lhes o fator semântico.

\section{Neologia de sentido}

Guilbert (1975) chama de neologia semântica "toda mudança de sentido que se produz em um dos três aspectos significantes do lexema sem que intervenha simultaneamente uma modificação na forma significante deste lexema" (GUILBERT, 1975, p. 21). O autor francês apresenta três casos de neologia semântica:

a) a primeira forma de neologia semântica situa-se no campo da retórica e aparece bcomo metáfora, sinédoque etc;

b) a segunda forma é a que afeta a categoria gramatical do lexema. É chamada, às vezes, de neologia por conversão. Convém destacar que o caráter semântico continua presente na modificação categorial;

c) a terceira forma de neologia semântica é qualificada como sociológica. Ocorre com termos técnicos que passam para o vocabulário geral. Neste caso, podese pensar em termos próprios de um jargão que são adotados por boa parte da comunidade linguística.

São exemplos de neologia semântica:

VALENTE, A. C. Aspectos semântico-discursivos da renovação lexical em época de Lava Jato e governo Bolsonaro 
Linha D’Água (Online), São Paulo, v. 32, n. 3, p. 79-97, set.-dez. 2019

a) Aquele político é um mala. / $\mathrm{O}$ dirigente do clube usou um laranja.

b) Que bela palavra é um não! / O amar é sublime.

c) Vou deletar aquele sujeito da minha vida. / Você não passa de um narciso.

\section{Neologia intertextual}

Nos estudos neológicos, a combinação de léxico e discurso também se materializa na neologia intertextual. $O$ neologismo com base nela criado pressupõe, em princípio, a existência de outro neologismo, a que se seguiram, em muitos casos, algumas criações neológicas com a mesma estrutura mórfica. Na neologia intertextual, a analogia é bastante utilizada no diálogo estabelecido entre o termo original e os que se seguiram. Em estudo anterior (VALENTE, 2010, p. 196), destaco a sequência analógica e intertextual a partir de "sambódromo": namoródromo, fumódromo, camelódromo, macumbódromo, sexódromo, beijódromo, cheiródromo e urinódromo, termos retirados da mídia carioca. Destaquei ainda a sequência, a partir do termo "passeata", dos neologismos carreata, bicicleata e motociata.

\section{Palavra pormenteau}

Segundo Houaiss (2001, p. 2108), é "a palavra resultante da combinação de partes de outras palavras, podendo entrar no vocabulário da língua”. Exemplifica com motel (motor + hotel) e lembra que algumas dessas palavras podem ser usadas em textos jocosos, como em passagens de Lewis Carroll, ou na prosa poética de Guimarães Rosa. Na etimologia, Houaiss (2001) destaca a presença de termos do francês, portemanteau ou mot-portemanteau, ou do inglês, portmanteau word.

Ao classificá-la de "palavra-mala", Figueiredo (2002) define-a como neologismo composicional criado a partir de uma "síntese disjuntiva" de duas palavras que, "em lugar de se sucederem linearmente, se imbricam e fundem as suas sílabas (normalmente homônimas e homógrafas) de maneira a, e quase sempre violando o interdito, formarem uma outra" (FIGUEIREDO, 2002, p. 524). Exemplifica com passagens de Mia Couto em "Último Voo do Flamingo", das quais destaco:

VALENTE, A. C. Aspectos semântico-discursivos da renovação lexical em época de Lava Jato e governo Bolsonaro 
a) "Aquelas ocavidades pareciam recém recentes", com a fusão de - ca da palavra oca e do fragmento - ca da palavra cavidade;

b) "O indivíduo se interpôs, pedinchorão" em que se amalgam as duas palavras (perdinchão + chorão) a partir do fragmento comum -ch

Figueiredo (2002) acrescenta que a essas novas unidades denominativas, uma vez que partem da fusão de outras unidades da língua, "é-lhes assegurado um reconhecimento colectivo por parte do leitor que não é fácil de decodificar” (FIGUEIREDO, 2002, p. 525). Lembra que, semântica e pragmaticamente, a originalidade da "palavra-mala" "vem de que ela significa sempre uma co-predicação: $X$, a palavra nova, é ao mesmo tempo A e B" (FIGUEIREDO, 2002, p. 525). Entende que um pedinchorão é, simultaneamente, pedinchão e chorão.

A autora observa que há, assim,

Um constante trabalho cognitivo a operar pelo leitor que não é despiciendo: tem, em primeiro lugar, que identificar a referência virtual, o conceito base dos dois termos da palavra-mala; seguidamente, e porque a actualização do referente não se faz a partir da soma dos sentidos dicionarizados, tem de recriar, em potência, um novo conceito para o novo referente de acordo com o contexto situacional (FIGUEIREDO, 2002, p. 525)

\section{Análise do corpus}

\section{1 lavajatismo}

Chego ao ponto. Porque não há um só dia em que olavajatismo - talvez o mais influente fenômeno revolucionário (não é elogio) da história brasileira - não reúna a assessoria de que dispõe para gritar que a luta anticorrupçẫo está em risco; e isto enquanto um país paralisado, em depressão políti$\mathrm{ca}$, consente com o vale-tudo virtuoso que, para prender bandidos, dilapida a ordem legal, planta a suspeição generalizada e esgarça o tecido social.

\section{Fig. 1}

Carlos Andreazza, O Globo, 23 jul. 2019.p. 3

VALENTE, A. C. Aspectos semântico-discursivos da renovação lexical em época de Lava Jato e governo Bolsonaro 
O neologismo parte de uma composição por justaposição (lava+jato) e chega a uma derivação sufixal (lavajato+-ismo). Cabe destacar que o sufixo -ismo é comumente empregado com o significado de "crença/doutrina/religião" (budismo, catolicismo, capitalismo, socialismo). $\mathrm{O}$ autor utiliza o termo para criticar abusos na condução do processo uma vez que os condutores da operação "lava jato" não aceitam questionamentos (“[...] não há um só dia em que o lavajatismo [...] não reúna a assessoria de que dispõe para gritar que a luta anticorrupção está em risco"). O valor semântico do sufixo combina "crença" e "doutrina" no neologismo, o que leva, segundo o autor, um país paralisado a assistir ao "vale-tudo virtuoso que, para prender bandidos, dilapida a ordem legal”.

\subsection{Vaza Jato}

\section{A Vaza Jato expôs uma grande fissura dessa couraça.}

Fig. 2

C.H. Mendes, Época, ed. 1098, 22 jul. 2019, p. 82

A expressão utilizada por Conrado Hübner Mendes tem valor irônico-discursivo no jogo intertextual com outra expressão - Lava Jato - já popularizada na sociedade brasileira. O neologismo "Vaza Jato" remete à divulgação, pelo site Intercept Br, dos diálogos entre juízes e procuradores, comandantes da operação "Lava Jato”. O vazamento dos diálogos pelo site, dirigido pelo jornalista Glenn Greenwald, revelou a parcialidade dos responsáveis pela operação "Lava Jato", que não admitiam contestação ("A Lava Jato já foi o álibi perfeito. Forçava-nos todos a uma camisa de força: ou se é defensor da Lava Jato ou se é defensor da corrupção. Interditou a crítica"). $\mathrm{O}$ autor denuncia que a operação Lava Jato ultrapassou os limites da lei: perdeu-se em seus desmandos. Conclui que "A Vaza Jato fez incontornável a corrupção que preferíamos não ver. O negacionismo impediu correções de rota”. 
Linha D’Água (Online), São Paulo, v. 32, n. 3, p. 79-97, set.-dez. 2019

\section{3 bolsonarês}

$\mathbf{N}$ a quarta-feira 15 de maio, quem abria os grandes portais de jornalismo do país deparava com o que, em política, costuma-se chamar de tempestade perfeita. As manchetes mostravam as ruas de 160 cidades brasileiras cheias com protestos contra a tesoura na Educação. Também era notícia a quebra de sigilo bancário do enrolado Flávio Bolsonaro. Iniciativas do Ministério Público Federal contra os cortes - contingenciamento, em bolsonarês - e contra o decreto das armas também eram destaque. E, por fim, o quadro era completado por duas informações ruins para o bolso de todo brasileiro: a prévia do PIB do primeiro trimestre do ano indicava uma provável retração e o dólar disparava, deixando o patamar de R\$ 4 para trás. Como os aviões, presidentes muitas vezes também caem nessas tempestades perfeitas. E Brasília já farejou isso.

Fig. 3

Época, ed. 1090, 27 maio 2019, p. 28

O sufixo -ês provém do sufixo latino -ense, que gerou duas formas em português - -ense e - $\hat{s}$ - para indicar origem, naturalidade. Por sua vez, o sufixo -ês passou a ter duplo uso na língua portuguesa: indica "origem, naturalidade" (francês, dinamarquês) ou "linguagem característica de" (internetês, juridiquês). No segundo uso, pode apresentar valor pejorativo (economês, linguistiquês).

O neologismo contém o sufixo na nova acepção: indica a linguagem característica de Bolsonaro, do governo Bolsonaro, do bolsonarismo. $\mathrm{O}$ autor registra que iniciativas do Ministério Público Federal contra cortes são denominadas "contingenciamento, em bolsonarês”. A construção neológica denuncia que os significados das palavras normalmente aceitos no convívio social, adquirem outros valores na linguagem do poder vigente: o bolsonarês.

VALENTE, A. C. Aspectos semântico-discursivos da renovação lexical em época de Lava Jato e governo Bolsonaro 
Linha D’Água (Online), São Paulo, v. 32, n. 3, p. 79-97, set.-dez. 2019

\title{
5.4 toffolês
}

CONRADO HUBNER MENDES E DOUTOR EM DIREITO E PROFESSOR DA USP

\section{COLABORAČ̃̃O PREMIADA (EM TOFFOLES)}

\begin{abstract}
Notoffolês, as letras enganam. Dialeto arranhado do juridiquês, essa língua estrangeira enfeitada por muito arcaísmo, pouca concisão e nenhuma objetividade, o toffolês se decifra mais pelos trejeitos e fraquezas da pessoa que fala do que pela literalidade. Se o húngaro é a única língua que o diabo respeita, o toffolês talvez seja a única língua que respeita Bolsonaro. Uma língua que faz pinta de conteúdo para que o vácuo de pensamento passe despercebido.
\end{abstract}

Fig. 4

C.H. Mendes, Época, ed. 1099, 29 jul. 2019 p. 82

O neologismo apresenta a mesma estrutura mórfica de bolsonarês. Utilizase o sufixo -ês combinado com o radical de um substantivo próprio (Toffoli+-ês). Refere-se à linguagem característica de Dias Toffoli, atual presidente do Supremo Tribunal Federal. O autor é bastante crítico - e, para tanto, vale-se de uma ironia discursiva - em relação ao linguajar do Presidente do STF. Hübner recorre à neologia intertextual ao inserir "toffolês" no "juridiquês" e atribui, consequentemente, àquele valor pejorativo existente neste. Afirma o autor que "Dialeto arranhado do juridiquês, essa língua estrangeira enfeitada por muito arcaísmo, pouca concisão e nenhuma objetividade, o toffolês (o grifo é nosso) se decifra mais pelos trejeitos e fraquezas da pessoa que fala do qual pela literalidade”.

VALENTE, A. C. Aspectos semântico-discursivos da renovação lexical em época de Lava Jato e governo Bolsonaro 
Linha D’Água (Online), São Paulo, v. 32, n. 3, p. 79-97, set.-dez. 2019

\section{5 bolsofamília}

Da Declaração Universal dos Direitos do Homem o homem como designação para o ser humano -, reproduzo abaixo os cinco primeiros artigos:

Artigo 10: "Todos os homens nascem livres e iguais em dignidade e direitos. São dotados de razão e consciência e devem agir em relação uns aos outros com espírito de fraternidade".

Pensem nesse artigo quando forem dar aquela "lacrada" no Twitter - como eu odeio essa palavra - ou quando estiverem prestes a regurgitar qualquer dos impropérios da Bolsofamília.

Fig. 5

Mônica de Bolle, Época, ed. 1090, 27 maio 2019, p. 36

O neologismo estabelece uma relação intertextual com "Bolsa Família”. A inovação de Mônica Bolle merece duas considerações linguístico-discursivas:

$1^{a}$ ) há um traço paronímico entre os dois terços;

2a) em Bolsa Família, ocorre justaposição;

$3^{a}$ ) em Bolsofamília, ocorre, inicialmente abreviação ("Bolso" é uma forma reduzida de "Bolsonaro") e, a seguir, aglutinação.

Entre os casos de aglutinação, Bechara (2001) destaca o de uso de um radical com determinado sentido desde que esteja ligado a outro radical, como se verifica com -cola, significando "habitante" em "agrícola", "lunícola". Isoladamente, -cola teria outro significado. Tal caso também ocorre com "Bolso" como forma abreviada de "Bolsonaro". Como forma independente, "bolso" tem outro significado.

Convém ressaltar que a autora se vale da ironia discursiva com a construção neológica ao mostrar que Bolsonaro atua em família (com os três filhos) e para a família, diferente do que ocorre no projeto Bolsa Família.

VALENTE, A. C. Aspectos semântico-discursivos da renovação lexical em época de Lava Jato e governo Bolsonaro 
Linha D’Água (Online), São Paulo, v. 32, n. 3, p. 79-97, set.-dez. 2019

\section{6 magistocracia}

\begin{abstract}
A Lava Jato turbinou a blindagem da magistocracia. Tornou-se símbolo incorruptível de moralidade e gozou da presunção absoluta de legalidade. Não se testa sua legalidade, presume-se. Começou quando o Tribunal Regional Federal da $4^{a}$ Região (TRF-4), na primeira oportunidade de impor balizas à operação, adotou uma extravagante tese de exceção: "soluções inéditas para casos inéditos", nas palavras do desembargador.
\end{abstract}

Fig. 6

C.H. Mendes, Época, ed. 1098, 22 jul. 2019, p. 82

O termo vem sendo utilizado, no jornalismo político, de forma depreciativa. Constituído de duas bases (magist + -cracia), o neologismo adquire valor semânticodiscursivo que destoa das formações mais comuns com o radical -cracia, de origem grega, com o significado de "poder". Tal emprego encontra-se nos seguintes exemplos: democracia, aristocracia, plutocracia, burocracia. Nestes casos, inexiste o valor pejorativo verificado em "magistocracia". O autor critica, veementemente, juízes e procuradores que não aceitam limites e se colocam, às vezes, acima da própria lei.

Alguns morfólogos têm observado que o radical, segundo elemento da composição, pode funcionar com valor sufixal. Gonçalves registra que "o português atual vem se caracterizando pelo emprego de radicais neoclássicos que se transformaram em sufixos" (2016, p. 48). Cita como exemplos -logo, -metro, -latra e -dromo. A eles podemos acrescentar, certamente, cracia.

VALENTE, A. C. Aspectos semântico-discursivos da renovação lexical em época de Lava Jato e governo Bolsonaro 
Linha D’Água (Online), São Paulo, v. 32, n. 3, p. 79-97, set.-dez. 2019

\subsection{Bolsonóquio}

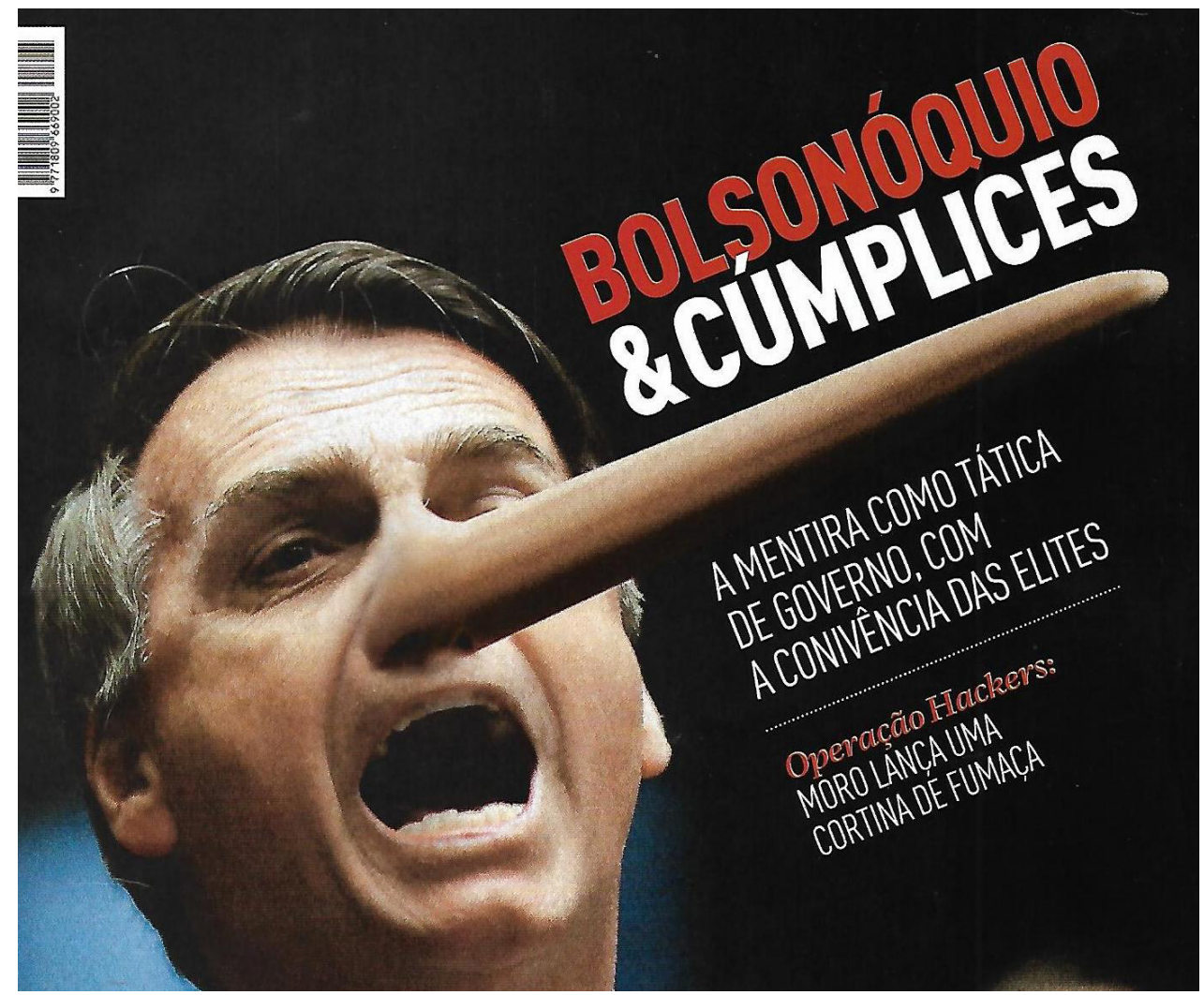

Fig. 7

Carta Capital, ed. 1065, 31 jul. 2019, capa

A matéria de capa da revista Carta Capital traz, na linguagem verbal, a expressão "BOLSONÓQUIO \& CÚMPLICES" combinada com a imagem do Presidente da República, Jair Bolsonaro, equiparado a Pinóquio. A linguagem não verbal mostra o nariz bastante alongado e, sob ele a frase "A MENTIRA COMO TÁTICA DE GOVERNO, COM A CONVENIÊNCIA DAS ELITES”.

BOLSONÓQUIO é um exemplo de palavra-valise, portmanteau ou blend. Surge da combinação Bolsonaro + Pinóquio. O neologismo denuncia a tática governamental de mentir, sistematicamente, em sua atuação política. Cabe destacar que, não obstante, na história original de Pinóquio que narra a evolução do boneco para ser humano, acabou prevalecendo a ideia de que o nariz crescia a cada mentira contada. A capa da revista explora a versão corrente com um enorme - e desproporcional - nariz de Bolsonaro.

VALENTE, A. C. Aspectos semântico-discursivos da renovação lexical em época de Lava Jato e governo Bolsonaro 
Linha D’Água (Online), São Paulo, v. 32, n. 3, p. 79-97, set.-dez. 2019

\subsection{Bolsolândia}

Lula não inventou a corrupção nem Dilma, o ridículo. Tampouco é sua a invenção da falta de compostura, civilidade e empatia. Mas é preciso que se dê conta de que governa o Brasil, não a Bolsolândia. Que 57 milhões de brasileiros o escolheram porque queriam no poder um "homem comum", com aqueles princípios morais tão escassos nos governos anteriores. E estes sete meses não fizeram jus a essa esperança.

Fig. 8

Eduardo Afonso, O Globo, 2 ago. 2019, p. 3

O neologismo utilizado por Eduardo Afonso traz referências intertextuais. O segundo elemento mórfico, -lândia, originário do inglês land (com significado de "terra", "terreno", "região", "país") tem uso consagrado em "Disneylândia", "Cinelândia" etc. Sobre tal uso, registra o dicionário eletrônico Houaiss (2009):

elemento de composição

pospositivo, do teutônico comum, como 'terra, país, região etc.', extremamente freq. em topônimos das línguas anglo-saxãs, alatinados tardiamente com o recurso do suf. -ia de locativos pátrios; em port., além de topônimos como Groenlândia, Finlândia, Jutlândia, tem servido para a form. ad hoc de muitos top. brasileiros, bem como para palavras ad hoc de valor afetivo e pitoresco, como pagolândia, gurilândia, brotolândia, bostolândia etc., pelo menos no Brasil.

Mais recentemente, vem sendo empregado com valor semântico-discursivo para críticas nos campos político, cultural e econômico e aí se insere "bolsolândia". O termo decorre da combinação de Bolso (forma abreviada de "Bolsonaro") e o elemento de composição lândia. O autor critica o Presidente da República, ao the dirigir uma carta com o vocativo "Prezado Jair", alertando-o para a necessidade de governar o país ao afirmar que "Mas é preciso que dê conta de que governa o Brasil, não a Bolsolândia”. Afinal, aqui é a terra dos brasileiros, e não dos bolsonaristas.

VALENTE, A. C. Aspectos semântico-discursivos da renovação lexical em época de Lava Jato e governo Bolsonaro 
Linha D’Água (Online), São Paulo, v. 32, n. 3, p. 79-97, set.-dez. 2019

\subsection{O ZERO ZERO}

O ZERO ZERO

AS INFLAMADAS

OPINIÖES DO MAIS

LONGEVO ASSESSOR

DE BOLSONARO

por Jussara Soares

e Gustavo Maia
38. CONSELHEIRO DESBOCADO

O ZERO ZERO

$O$ assessor mais antigo

de Jair Bolsonaro quer

que o presidente coloque o

Congresso contra a parede

Fig. 9

Época, ed. 1090, 27 maio 2019, p. 38-39

A construção vem marcada pela repetição do termo Zero, fenômeno chamado de reduplicação nos estudos dos processos de formação de palavras quando há valor onomatopaico. Bechara (1999) afirma que a Reduplicação, também chamada Duplicação Silábica, "consiste na repetição de vogal ou consoante, acompanhada quase sempre de alternância vocálica, para formar uma palavra imitativa" (BECHARA, 1999, p. 371). Exemplifica com "tique-taque", "reco-reco" e "pingue -pongue". No caso de "Zero Zero", a reduplicação não apresenta tal valor, mas sim uma inovação semântico-discursiva. Constitui um exemplo de neologia semântica no contexto político em que foi empregado.

Cabe relembrar que o atual Presidente da República governa o país com grande participação dos seus três filhos homens: Flávio, Carlos e Eduardo. Eles também foram eleitos e atuam, respectivamente, como senador, vereador e deputado federal. O Presidente Jair Bolsnoraro costuma chamá-los, respectivamente, de Zero Um, Zero Dois e Zero Três. A matéria da revista Época refere-se a Waldir Ferraz, o aliado mais antigo de Bolsonaro. Já na chamada de capa, a revista destaca "as inflamadas opiniões do mais longevo assessor de Bolsonaro", longevidade que justifica a denominação "Zero Zero". A matéria menciona, ainda, que Ferraz é assessor de Bolsonaro desde os anos 1980. Após a eleição, ele sugeriu ao Presidente "jogar o povo contra o Congresso". Com base na teoria de Guilbert, pode-se identificar uma neologia semântica no plano retórico, na figuração de linguagem em

VALENTE, A. C. Aspectos semântico-discursivos da renovação lexical em época de Lava Jato e governo Bolsonaro 
Linha D’Água (Online), São Paulo, v. 32, n. 3, p. 79-97, set.-dez. 2019

“Zero Zero". Acrescente-se a isso, o valor irônico-argumentativo na apresentação aos leitores de uma figura polêmica, tal qual os filhos do Presidente, no trato das questões políticas. A revista mostra que essa prática vem de longe e sempre esteve no entorno de Bolsonaro.

\subsection{0 canelada}

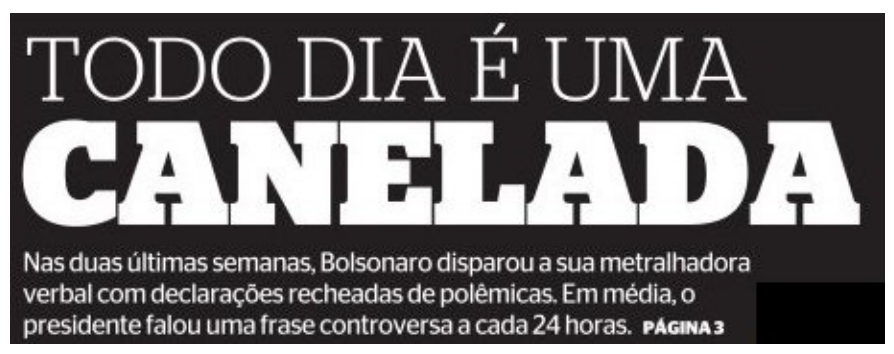

Fig. 10

Extra, 31 jul. 2019, capa

O termo constitui mais um caso de neologia semântica. Existe registro em dicionário para o substantivo "canelada", "pancada na canela da perna"(Aurélio, Houaiss e Caldas Aulete). Não é, portanto, um significante novo e ainda pode significar, como adjetivo, "em forma de canela"(malha canelada). Esse emprego deve estar ligado ao terceiro significado de "canela", no dicionário Aurélio: 1. árvore, cuja casca se usa em especiaria; 2. a parte da perna entre o joelho e o pé; 3. pequeno canudo ou bobina em que se enrola o fio para tecelagem. Cabe acrescentar o significado no jargão do futebol em que "dar uma canelada, ou de canela" significa "executar mal a jogada, não ter controle/domínio da bola”, uma vez que, por ser um osso, a canela não permite "matar a bola, dominá-la".

A neologia semântica dialoga, na manchete do jornal Extra, com o sentido já empregado no futebol para fazer a crítica ao mau desempenho de Bolsonaro na política. Ele também não tem domínio sobre o que fala. Na sua "metralhadora verbal", ataca os que pensam ou agem diferentemente do que ele quer. Diz, sem qualquer cerimônia, frases polêmicas como "Pretendo beneficiar filho meu, sim. Se puder, dar filé mignon”, “Dentre os governadores de Paraíba, o pior é o do Maranhão", "Se o presidente da OAB quiser saber como o pai desapareceu no período

VALENTE, A. C. Aspectos semântico-discursivos da renovação lexical em época de Lava Jato e governo Bolsonaro 
Linha D’Água (Online), São Paulo, v. 32, n. 3, p. 79-97, set.-dez. 2019

militar, eu conto para ele", entre outras barbaridades. Com base na teoria de Guilbert, pode-se entender que a neologia semântica combina dois tipos: o retórico, a figuração de linguagem (por metáfora); o sociológico, transferência de uma área (esporte) para outra (política).

\section{Conclusão}

Os estudos lexicológicos, no que diz respeito às criações neológicas, têm encontrado campo fértil na linguagem midiática. A nossa língua se renova, diariamente, nos textos publicados em jornais e revistas. As pesquisas acadêmicas registram muitos neologismos formais ou vocabulares e, mais recentemente, vêm apresentando neologismos semânticos, o que revela uma tendência em se trabalhar, também, com a função poética no jornalismo escrito. $\mathrm{O}$ trabalho aqui exposto buscou destacar e analisar tanto as construções criativas na neologia de forma como na neologia de sentido. Chamou a nossa atenção o fato de a criatividade manifestar-se em terreno considerado, comumente, árido: a área política.

Os temas dessa natureza costumam ser considerados, inicialmente, pouco propícios a análises que valorizam o aspecto criativo da linguagem. Afinal, falar de Lava Jato e Governo Bolsonaro não parece ser algo atraente ou motivador. Cabe, então, ressaltar que o corpus analisado não só contemplou o que nos motiva e fascina nas criações neológicas, na sua força inovadora, mas também permitiu-nos refletir sobre questões sociopolíticas fundamentais para a luta diária da sociedade brasileira no que concerne à sua sobrevivência. São assuntos de capital importância nas nossas vidas, com sérias consequências para o nosso trabalho e para o nosso convívio social. Concluímos que, não obstante haver problemas na motivação para tratar de alguns temas, a nossa língua sempre encontra, na sua rebeldia e na sua inventividade, recursos para traçar novos caminhos, de forma crítica e com tom irônico, com o intuito de denunciar nossas mazelas no meio político.

VALENTE, A. C. Aspectos semântico-discursivos da renovação lexical em época de Lava Jato e governo Bolsonaro 
Linha D’Água (Online), São Paulo, v. 32, n. 3, p. 79-97, set.-dez. 2019

\section{Referências}

AULETE, C. Novíssimo Aulete: Dicionário Contemporâneo da Lingua Portuguesa. Rio de Janeiro: Lexikon, 2011.

BASILIO, M. Teoria Lexical. São Paulo: Ática, 1987.

BECHARA, E. Moderna gramática portuguesa. Rio de Janeiro: Lucerna, 2001.

FERREIRA, A. B. de H. Norvo Dicionário Aurélio da Lingua Portuguesa. 2a ed. 18. Impressão. Rio de Janeiro: Nova Fronteira, 1993.

FIGUEIREDO, O. M. O ficcionário de O último Voo do Flamingo, de Mia Couto. Porto: Revista da Faculdade de Letras, II série. Volume IX, 2002.

GONÇALVES, C. A. Atuais tendências em formação de palavras. São Paulo: Contexto, 2016.

GUILBERT, L. La créativité lexicale. Paris: Larousse, 1975.

HENRIQUES, C.C. Morfologia.Rio de Janeiro: Campus, 2007.

HOUAISS, A. Dicionário Houaiss da Lingua Portuguesa. Rio de Janeiro, Ed. Objetiva, 2001. Dicionário Eletrônico Houaiss. Rio de Janeiro: Editora Objetiva, 2009.

LAROCA. M. N. de C. Manual de morfologia portuguesa. São Paulo: Pontes, 1994.

MONTEIRO, J. L. Morfologia portuguesa. Fortaleza: Editora da UFC, 1987.

VALENTE, A. C. Aspectos semântico-discursivos e intertextuais da neologia midiática. In: ALVES, I. M. (Org.). Neologia e neologismos em diferentes perspectivas. São Paulo: Paulistana, 2010, p. 185-201.

Recebido: 17/08/2019.

Aprovado: 06/10/2019.

VALENTE, A. C. Aspectos semântico-discursivos da renovacção lexical em época de Lava Jato e governo Bolsonaro 